\title{
Ultrasonic Evaluation of Temper-Embrittlement for Martensitic Stainless Steel
}

\author{
Cheng-Hsun Hsu ${ }^{1}$, Hwei-Yuan Teng ${ }^{2}$ and Sheng-Chien Chiu ${ }^{1}$ \\ ${ }^{1}$ Department of Materials Engineering, Tatung University, Taipei, Taiwan 104, R. O. China \\ ${ }^{2}$ Department of Mechanical Engineering, De Lin Institute of Technology, Taipei, Taiwan 237, R. O. China
}

This research studied the possibility of non-destructive detection of temper-embrittlement in tempered CA-15 martensitic stainless steel (MSS). It was found that secondary hardening phenomenon existed in tempering temperature range of 573-673 K for the MSS in this study. Ultrasonic responses, both in terms of acoustic velocity and attenuation, exhibited changes with respective to the microstructure variation. Microstructural constituent of chromium carbide $\left(\mathrm{Cr}_{23} \mathrm{C}_{6}\right.$ type) precipitates was found to have resulted in the temper-embrittlement of the MSS and also was responsible for the changes of the ultrasonic behavior of the material.

(Received June 20, 2003; Accepted September 4, 2003)

Keywords: temper embrittlement, ultrasonic evaluation, martensitic stainless steel

\section{Introduction}

Martensitic stainless steel (MSS) possesses high temperature strength and corrosion resistance and it is suitable for engineering components in highly stressed application, such as turbines and gas distributor heads. ${ }^{1)}$ In general, MSS is heat treated by austenitizing and tempering processes to achieve desirable mechanical properties such as the erosion wear resistance. ${ }^{2)}$ However, this material exhibited temperembrittlement behavior when tempered in the temperature range of 643 to $868 \mathrm{~K}^{3)}$

Ultrasonic technique is not only used to detect as voids, cracks, inclusions, precipitates, etc., but also applicable for material characteristics evaluation. Acoustic velocity and attenuation are commonly used for such purposes. ${ }^{4)}$ Acoustic velocity of an ultrasonic wave as it propagates through solid material is affected by elastic modulus $(E)$, density $(\rho)$ and Poisson's ratio $(\mu)$. The relationship between these elastic constants and longitudinal or transverse velocity, $V_{\mathrm{L}}$ or $V_{\mathrm{T}}$, of ultrasonic wave can be expressed as follows: ${ }^{5)}$

$$
\begin{aligned}
V_{\mathrm{L}} & =\sqrt{\frac{E(1-\mu)}{\rho(1+\mu)(1-2 \mu)}} \\
V_{\mathrm{T}} & =\sqrt{\frac{E}{2 \rho(1+\mu)}}
\end{aligned}
$$

The above equations imply that the acoustic velocity is also a constant value and thus is characteristic to a material in a specific state. That is to say, microstructural changes of the material can cause the alteration of ultrasonic velocity.

When an ultrasonic wave travels through a medium, its amplitude $(A)$ or intensity $(I)$ will decay exponentially with respective to the distance $(D)$ of the sound propagation. ${ }^{5)}$ The relationship can be written as:

$$
A=A_{0} \exp (-\alpha D), \quad \text { or, } \quad I=I_{0} \exp (-\alpha D)
$$

where $A_{0}$ and $I_{0}$ are the initial sound amplitude and the intensity, respectively. The attenuation coefficient $(\alpha)$ quantitatively can further be described by the following equation: $:^{5,6)}$

$$
\alpha(f)=\frac{20[\log (A 1 / A 2)+2 \log R]}{2 d},
$$

where $\alpha(f)$ is in $\mathrm{dB} / \mathrm{mm}, A 1$ and $A 2$ are peak amplitudes of the first and second transmitted pulses in $\mathrm{mm}$, and $d$ is the tested specimen thickness, also in mm. $R=(1-\eta) /(1+\eta)$ is the reflection coefficient of the coupling plane, and $\eta$ is the acoustic impedance of the coupling plane. The attenuation coefficient of ultrasonic wave is affected by the absorption (influenced by dislocation damping, magnetic resistance, and the thermal elasticity) and scattering (influenced by grain boundary, voids, inclusion, second phase particles, cracks, etc.). ${ }^{7)}$ The attenuation coefficient is also a function of detective frequency.

Thus, it is purpose of this research to study the relationship between ultrasonic velocity and attenuation vs. microstructure and mechanical properties of MSS tempered at various tempering temperatures such that the material property characterization can be evaluated by non-destructive ultrasonic technique.

\section{Experimental Procedure}

\subsection{Material and heat treatment}

In this study, CA-15 cast MSS plates of $32 \mathrm{~mm}$ in thickness produced by a commercial foundry was used as the experimental material. Chemical composition of the material was analyzed by spectrometer to be: C: $0.14 \% \mathrm{C}, \mathrm{Si}: 0.34 \%$, Mn: $0.33 \%$, Cr: $12.1 \%$, Ni: $1.00 \%$, P: 0.017 , S: $0.001 \%$, Fe: Bal. (mass \%). This was found to be in conformance to CA15 chemical specification. Various specimens for mechanical testing and ultrasonic evaluation were machined from these casting plates and then subjected to various heat-treating schedules. The heat treatment procedure involved austenitizing, quenching, and tempering as shown in Fig. 1.

\subsection{Microstructural analysis}

Microstructures of the experimental specimens were analyzed by using scanning electron microscopy (SEM), electron probe microanalysis (EPMA), and transmission electron microscopy (TEM), respectively. An X-ray diffractometer (XRD) was used to identify the structural phase. The 


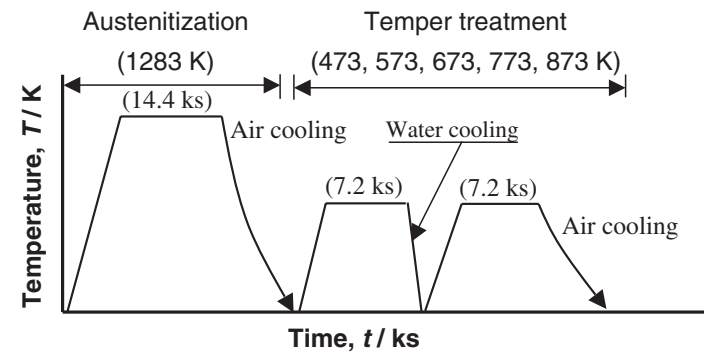

Fig. 1 Heat treatment processing of the experimental material.

specimens were polished and etched with Vilella's reagent $(5 \mathrm{~mL} \mathrm{HCl}+1 \mathrm{~g}$ Picric acid $+100 \mathrm{~mL}$ ethanol $)$ to reveal the microstructural features.

\subsection{Mechanical testing}

Hardness testing of the samples was performed by using a Vickers $(30 \mathrm{~kg}$ load) hardness tester. Five hardness readings were taken and averaged for each specimen. Tensile tests were carried out by using a dynamic testing machine (MTS model 810). Specimens for tensile testing were machined according to the sub-size tensile coupon to ASTM-E8M standard. ${ }^{8)}$ Impact tests were carried out by using a Charpy impact tester. Specimens for impact testing were machined to ASTM-E23 V-notch impact testing standard. ${ }^{9)}$ Three tests were performed and averaged to represent the tensile strength, elongation, and impact toughness of the experimental material in each heat-treated condition.

\subsection{Ultrasonic evaluation}

An ultrasonic A-scan pulsing instrument as attached to a gate monitor (Krautkramer model USIP 12 with DTM 12 attachment) for ultrasonic evaluation of the velocity and the first and the second pulses peak amplitudes ( $A 1$ and $A 2$ in Eq. 4) for attenuation coefficient calculation of the specimens. Ultrasonic probes with frequencies of $1 \mathrm{MHz}$ and $5 \mathrm{MHz}$ were used, and commercial motor oil was adopted as couplant for the ultrasonic contact-type testing in this experiment. Longitudinal wave was applied to evaluate the acoustic characteristics of each specimen at the same position before and after heat treatment. Five ultrasonic readings of each specimen were taken and averaged to represent the data obtained.

\section{Results and Discussion}

\subsection{Microstructure}

The microstructure of the experimental as-cast material mainly consisted of martensite and ferrite phases in the matrix with chromium carbide films around grain boundaries. SEM and EPMA micrographs of the as-cast sample are shown in Fig. 2(a). It can be seen clearly that there were $\mathrm{Cr}$ rich precipitates around the martensitic grain boundary. These carbides were largely eliminated by austenitizing at $1283 \mathrm{~K}$ for $14.4 \mathrm{ks}$ and then quenching, as shown in Fig. 2(b). Figure 2(c) shows the micrograph of the sample tempered at $673 \mathrm{~K}$. The microstructure has no obvious change, but the chromium content has a little raise at the grain boundary of EPMA micrograph. Furthermore, the ferrite islands started to
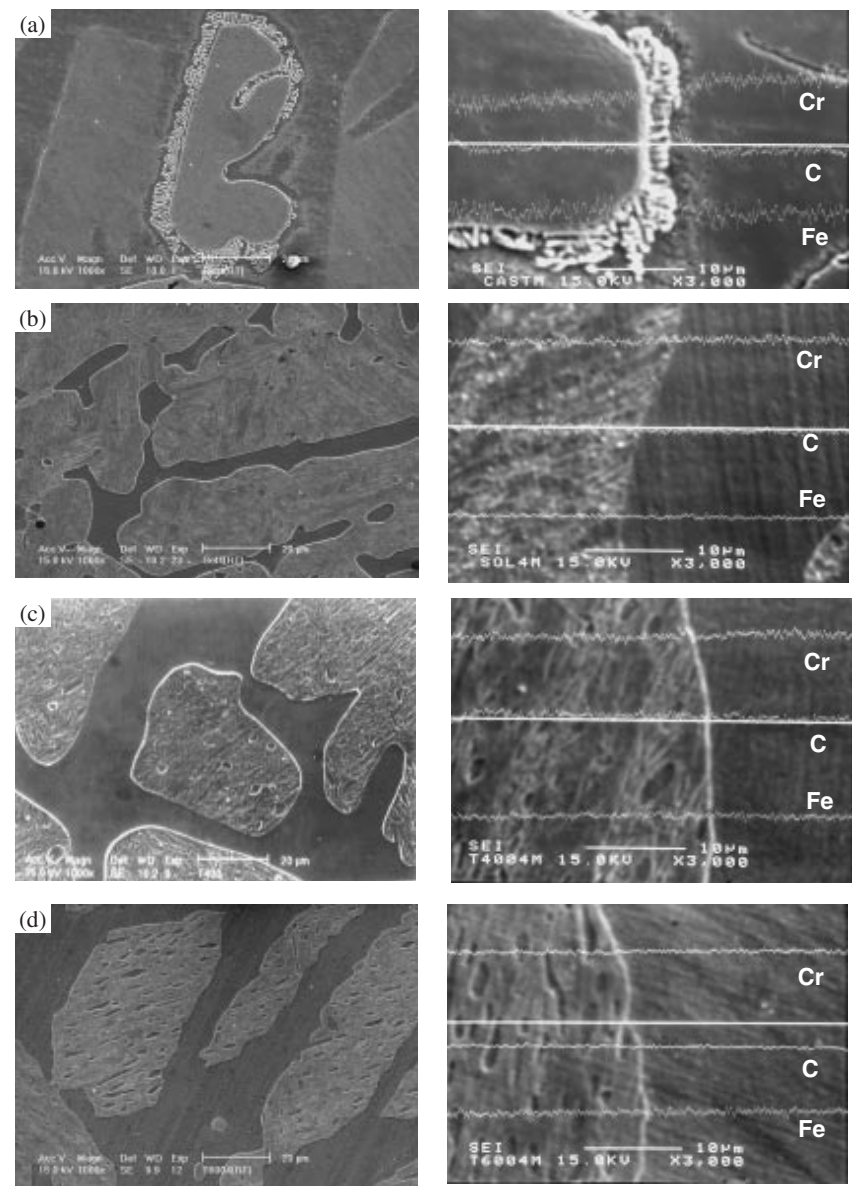

Fig. 2 SEM and EPMA scan of the experimental material: (a) as-cast, (b) as-quenched, (c) $673 \mathrm{~K}$-tempered, (d) $873 \mathrm{~K}$-tempered.

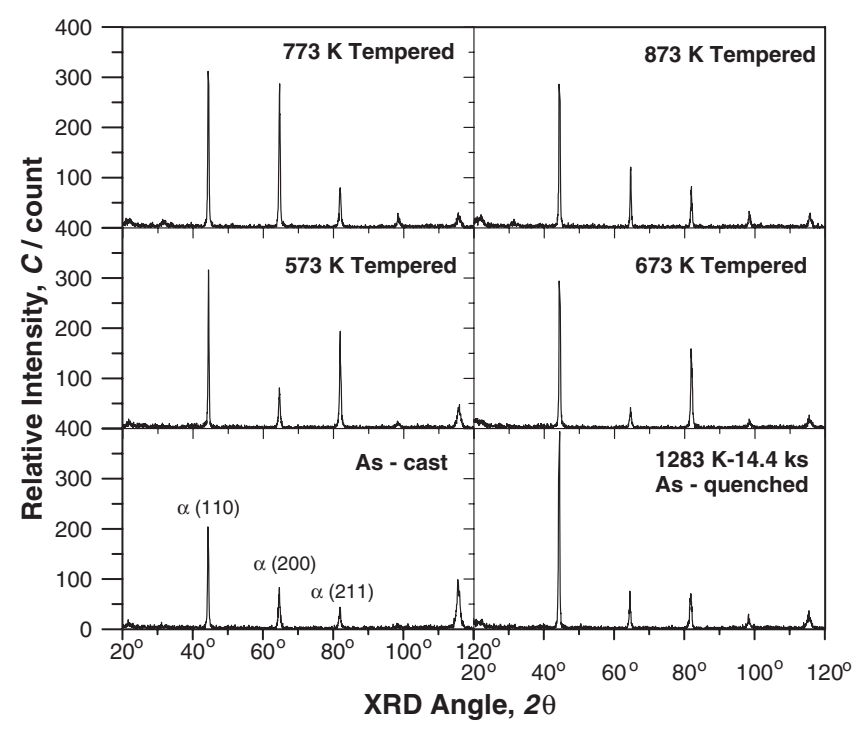

Fig. 3 XRD patterns of this material after different heat treatments.

precipitate in the martensitic grains. After tempering at $773 \mathrm{~K}$ and $873 \mathrm{~K}, \mathrm{Cr}$ and $\mathrm{C}$ elements were found to be uniformly dispersed in the matrix. Figure 2(d) shows the micrographs of sample tempered at $873 \mathrm{~K}$, where the more ferrite islands precipitated in the martensitic grains.

Figure 3 shows the XRD patterns of the material before and after the different heat treatments. It was found that 

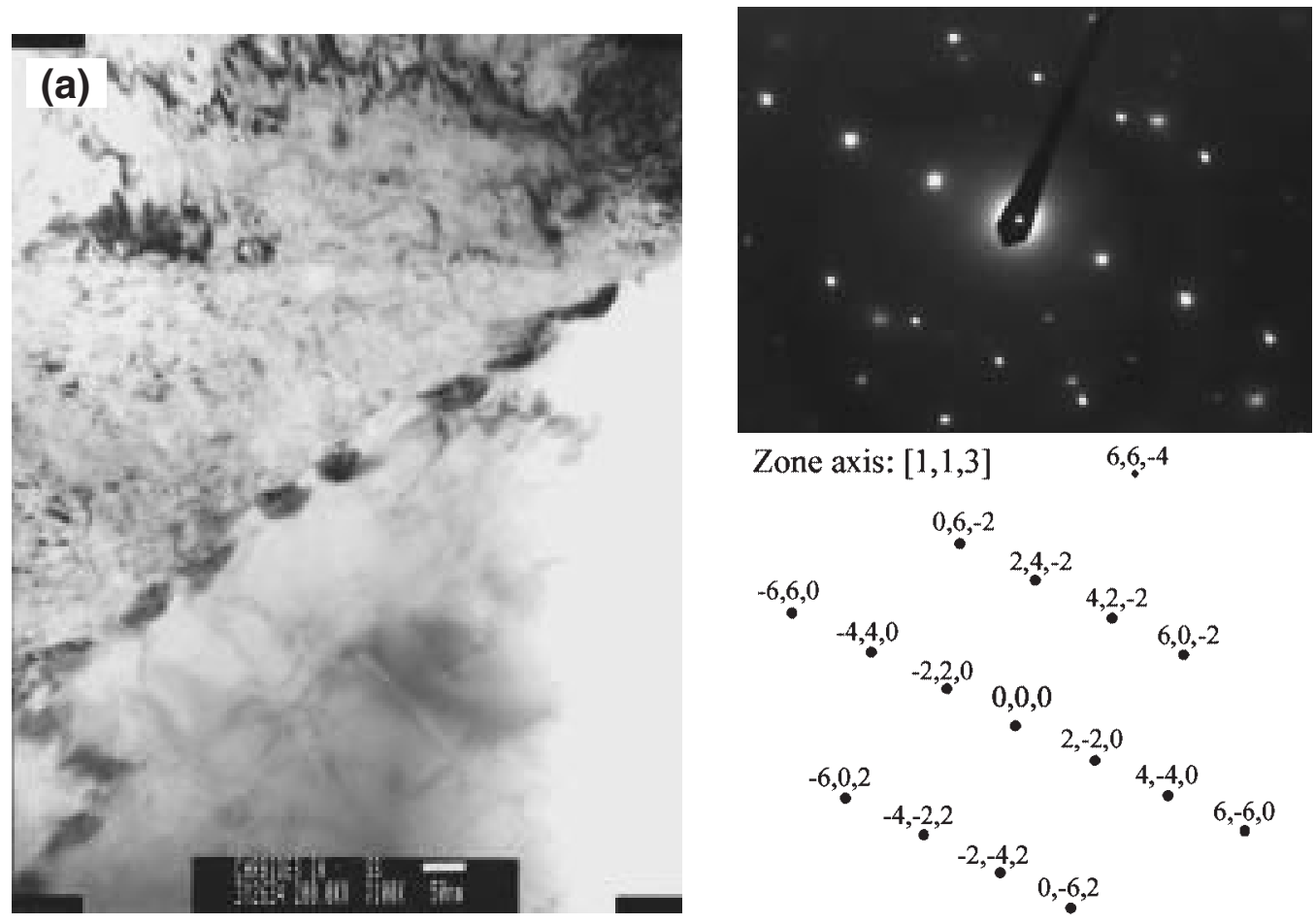

$-6,-6,4$
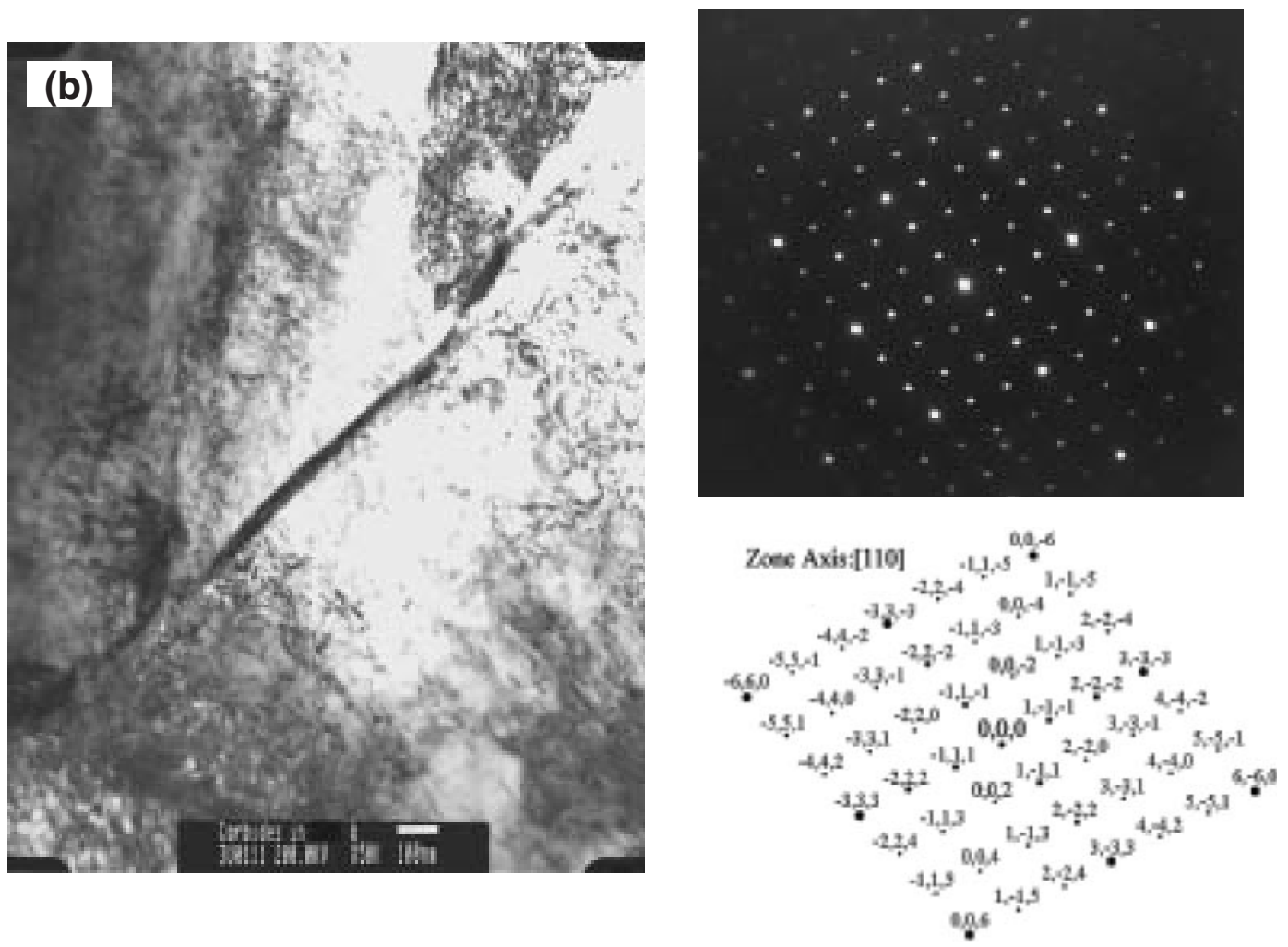

Fig. 4 TEM micrograph and EDP of the carbide precipitated in sample tempered at $673 \mathrm{~K}$ : (a) beaded-like carbide, (b) stringed-like carbide.

austenite was not retained in the matrices of as-cast and heat treated samples. The alloy carbide pattern was also not shown in the $673 \mathrm{~K}$ tempered sample because of the precipitated alloy carbide was too small to detect for XRD examination.

The TEM micrographs and electron diffraction pattern (EDP) of $673 \mathrm{~K}$ tempered sample are shown in Figs. 4(a) and (b). It can be found that the beaded-like and stringed-like carbides were precipitated at the grain boundary. The carbides identified from EDP were the $\mathrm{Cr}_{23} \mathrm{C}_{6}$ type carbide. The effects of these microstructural variation on the mechanical properties were further discussed in the following section. 
Table 1 Mechanical properties of the experimental material.

\begin{tabular}{|c|c|c|c|c|c|}
\hline Heat treatment & $\begin{array}{l}\text { Hardness } \\
\qquad(\mathrm{Hv})\end{array}$ & $\begin{array}{l}\text { Ultimate } \\
\text { strength } \\
\text { (U.T.S.) } \\
\text { (MPa) }\end{array}$ & $\begin{array}{c}\text { Elongation } \\
(\%)\end{array}$ & $\begin{array}{c}\text { Impact } \\
\text { toughness } \\
\text { (J) }\end{array}$ & $\begin{array}{c}\text { Elastic } \\
\text { modulus } \\
(\mathrm{GPa})\end{array}$ \\
\hline As-cast & 289 & 1017 & 5.0 & 4.5 & 206 \\
\hline As-quenched & 322 & 907 & 3.0 & 15 & 148 \\
\hline $473 \mathrm{~K}$-tempered & 316 & 980 & 4.5 & 17 & 149 \\
\hline 573 K-tempered & 354 & 1043 & 9.2 & 7.5 & 150 \\
\hline $673 \mathrm{~K}$-tempered & 358 & 1048 & 6.8 & 6 & 159 \\
\hline $773 \mathrm{~K}$-tempered & 296 & 824 & 15.6 & 16 & 168 \\
\hline $873 \mathrm{~K}$-tempered & 252 & 706 & 28.8 & 31 & 185 \\
\hline
\end{tabular}

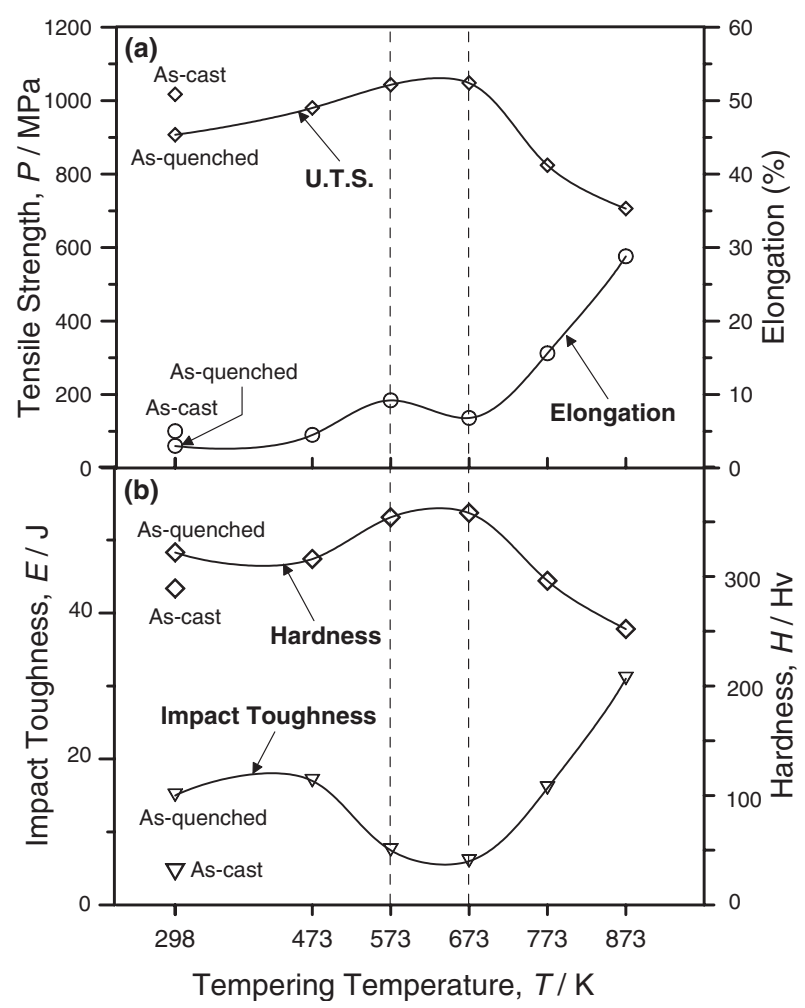

Fig. 5 Effect of the tempering treatment on the mechanical properties of the experimental material: (a) tensile strength and elongation, (b) hardness and impact toughness.

\subsection{Relationship between microstructure and mechan- ical properties}

The data of the mechanical properties of the as-cast, as quenched, and tempered MSS materials in this research are listed in Table 1 and depicted in Fig. 5. Due to the existence of Cr-rich carbide films around martensitic grains, toughness and ductility of the as-cast MSS were greatly impaired. Also, due to the existence of fresh martensite in the matrix of the as-quenched MSS, mechanical properties were actually not adequate for actual industrial application. The properties of the MSS after tempering were of importance and were further discussed below.

Figure 5 clearly shows the secondary hardening effect when MSS was tempered at temperature range of 573 and $673 \mathrm{~K}$ in this study. This resulted in the increase of hardness and strength, but ductility and especially impact toughness were greatly reduced. The $\mathrm{Cr}_{23} \mathrm{C}_{6}$ carbide precipitates around the grain boundary was responsible for this phenomenon.

Tempering beyond $673 \mathrm{~K}$ restored the ductility and toughness properties of the MSS, but strength and hardness appeared to drop, as can be seen in Figs. 5(a) and (b).

\subsection{Relationship between ultrasonic characteristics and mechanical properties}

3.3.1 Ultrasonic velocity

The data of ultrasonic velocity measured in various heattreatment states are listed in Table 2 and depicted in Fig. 6. It appeared that as the tempering temperature increased, ultrasonic velocity also increased accordingly. The increase of elastic modulus $(E)$ as shown in Table 1 and Fig. 7 might have contributed to this effect (the as-cast specimen was an exception due to the effect of carbide films around grain boundary). This behavior is in conformance with the eq. (1) that describes the relationship between ultrasonic velocity and elastic constants of materials.

At two different ultrasonic frequencies, i.e. $1 \mathrm{MHz}$ and $5 \mathrm{MHz}$, both Fig. 6 and Fig. 7 shows a acoustic velocity

Table 2 Ultrasonic velocity and attenuation of the experimental material.

\begin{tabular}{|c|c|c|c|c|}
\hline Ultrasonic probe & \multicolumn{2}{|c|}{$1 \mathrm{MHz}$} & \multicolumn{2}{|c|}{$5 \mathrm{MHz}$} \\
\hline Heat $_{\text {treatment }}^{\begin{array}{c}\text { Ultrasonic } \\
\text { response }\end{array}}$ & $\begin{array}{c}\text { Velocity, } V \\
(\mathrm{~m} / \mathrm{s})\end{array}$ & $\begin{array}{c}\text { Attenuation, } \alpha \\
(\mathrm{dB} / \mathrm{mm})\end{array}$ & $\begin{array}{c}\text { Velocity, } V \\
(\mathrm{~m} / \mathrm{s})\end{array}$ & $\begin{array}{c}\text { Attenuation, } \alpha \\
(\mathrm{dB} / \mathrm{mm})\end{array}$ \\
\hline As-cast & 5,912 & 0.0734 & 5,889 & 0.1538 \\
\hline As-quenched & 5,879 & 0.04971 & 5,877 & 0.12455 \\
\hline $473 \mathrm{~K}$-tempered & 5,898 & 0.04982 & 5,883 & 0.12419 \\
\hline $573 \mathrm{~K}$-tempered & 5,916 & 0.05313 & 5,891 & 0.13671 \\
\hline $673 \mathrm{~K}$-tempered & 5,917 & 0.05017 & 5,896 & 0.13441 \\
\hline 773 K-tempered & 5,928 & 0.04929 & 5,898 & 0.12753 \\
\hline 873 K-tempered & 5,945 & 0.04673 & 5,919 & 0.10899 \\
\hline Average & $\begin{array}{c}5,914 \pm \\
33\end{array}$ & $\begin{array}{c}0.053179 \pm \\
0.027\end{array}$ & $5,893 \pm 21$ & $\begin{array}{c}0.130026 \pm \\
0.045\end{array}$ \\
\hline Average velocity & \multicolumn{4}{|c|}{$5904 \pm 34 \mathrm{~m} / \mathrm{s}$} \\
\hline Average attenuation & \multicolumn{4}{|c|}{$0.091602 \pm 0.107 \mathrm{~dB} / \mathrm{mm}$} \\
\hline
\end{tabular}

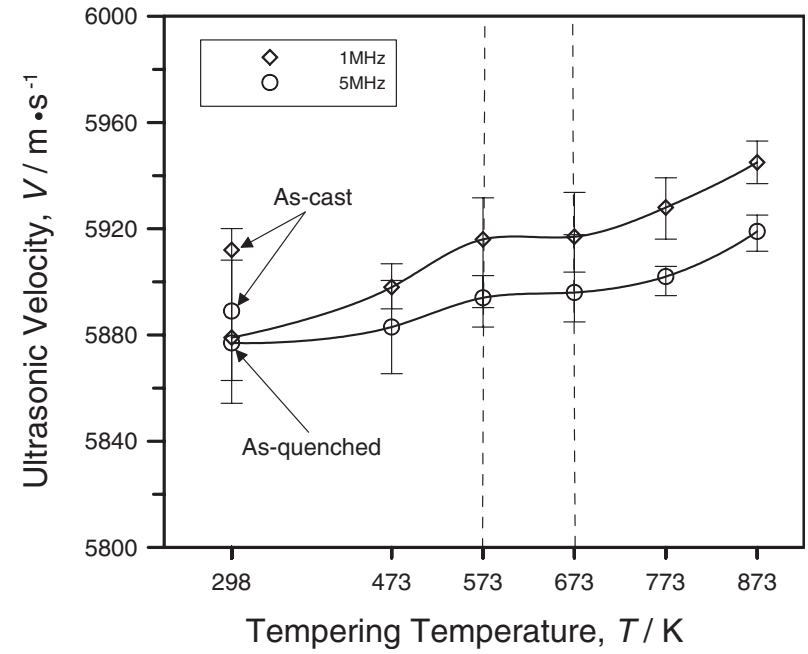

Fig. 6 The effect of tempering temperature on ultrasonic velocity of martensitic stainless steel, ultrasonic frequency of $1 \mathrm{MHz}$ and $5 \mathrm{MHz}$. 


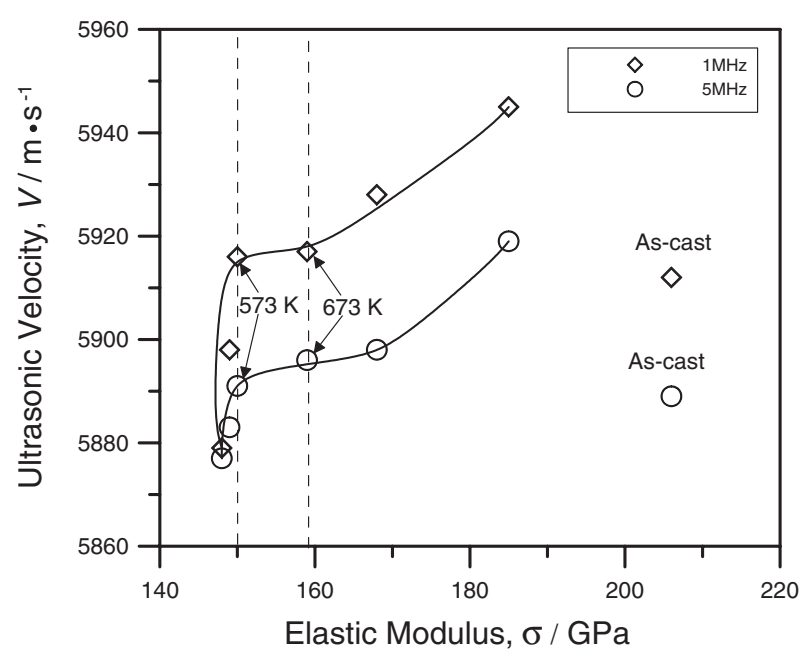

Fig. 7 The relationship between ultrasonic velocity and elastic modulus of the experimental material, ultrasonic frequency of $1 \mathrm{MHz}$ and $5 \mathrm{MHz}$.

plateau in the temperature range of $573-673 \mathrm{~K}$ where the secondary hardening effect occurred. This result implied that ultrasonic non-destructive technique could be used to detect temper-embrittlement phenomenon caused by the secondary hardening of tempered martensitic stainless steel. The precipitation of $\mathrm{M}_{23} \mathrm{C}_{6}$ carbides (especially for stringed-like carbide) around grain boundary might have hindered the ultrasonic wave propagation thus slowing down the increasing trend of acoustic transmission velocity as the tempering temperature went up. The plate, flake or string shape intermediate was more serious for slowing down the acoustic transmission velocity than that of globular shape intermediate. $^{10)}$

Incidentally, ultrasonic velocity at $1 \mathrm{MHz}$ appeared to be higher than that of the $5 \mathrm{HMz}$. Average velocity of the $1 \mathrm{MHz}$ was at $5914 \pm 33 \mathrm{~m} / \mathrm{s}$, while that of the $5 \mathrm{MHz}$ was at about $5893 \pm 21 \mathrm{~m} / \mathrm{s}$. The reason of this was unknown, perhaps from the electronic gain or loss of the instrument. At any rate, the overall average is at $5904 \pm 34 \mathrm{~m} / \mathrm{s}$ for this material at all different heat-treating states and ultrasonic probe frequencies in this study.

\subsubsection{Ultrasonic attenuation}

The variation of ultrasonic attenuation after different tempering treatments were listed in Table 2 and depicted in Fig. 8. The use of high frequency $5 \mathrm{MHz}$ probe resulted in high attenuation of $0.130026 \pm 0.045$ (vs. that of $0.0531 \pm$ 0.027 for $1 \mathrm{MHz}$ ). This was the result of higher the ultrasonic response at $5 \mathrm{MHz}$. However, the higher sensitivity also leads to greater scattering of the data obtained, as can be seen from Fig. 8.

On the $5 \mathrm{MHz}$ curve of the relationship between ultrasonic attenuation coefficient vs. tempering temperature in Fig. 8 a risen plateau appeared at the temperature range of 573-673 K. The carbides precipitated around grain boundary while material was tempered at this region, that promoted the boundary scattering and energy loss while ultrasonic wave propagation. This caused the ultrasonic attenuation coefficient increased. The similar effect of boundary carbides scattering was occurred at as-cast specimen too. The attenuation coefficient dropped with the increase in temper-

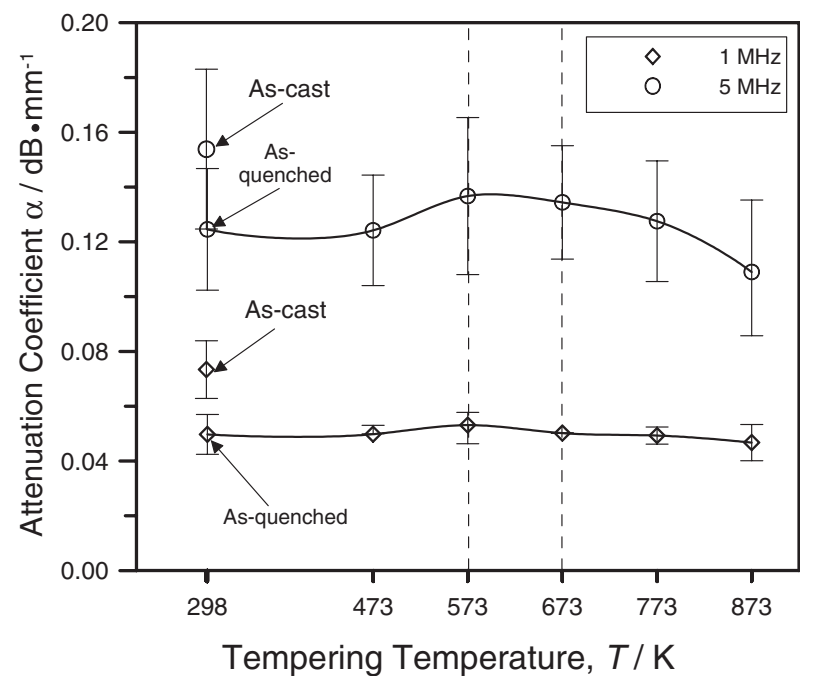

Fig. 8 The effect of tempering temperature on ultrasonic attenuation of martensitic stainless steel at different ultrasonic frequency of $1 \mathrm{MHz}$ and $5 \mathrm{MHz}$.

ing temperature above $673 \mathrm{~K}$ that resulted in dislocation number decreased and the ferrite islands (low dislocation density structure) precipitation. It was known that the dislocation in materials caused the ultrasonic wave absorption (damping of ultrasonic wave energy) and attenuation rise. ${ }^{7)}$ Therefore, the attenuation coefficient decreased in specimens tempered above $673 \mathrm{~K}$. The plateau region was not shown at the $1 \mathrm{MHz}$ curve. This implied that if ultrasonic attenuation is to be used as a method to determine the occurrence of temper-embrittlement phenomenon, higher frequency ultrasonic probe such as $5 \mathrm{MHz}$ is recommended and needed. This is probably because at higher frequency the smaller acoustic wave length resulted in the greater scattering of ultrasonic wave propagation thus the attenuation coefficient variations were more pronounced.

\section{Conclusions}

The following conclusions were obtained from this study of the relationship between ultrasonic characteristics vs. mechanical property and temper-embrittlement behavior of CA-15 martensitic stainless steel (MSS):

(1) MSS exhibited temper-embrittlement phenomenon as $573-673 \mathrm{~K}$ in this study due to $(\mathrm{Cr}, \mathrm{Fe})_{23} \mathrm{C}_{6}$ carbides precipitation that contributed to the secondary hardening effect of the tempered MSS.

(2) The occurrence of temper-embrittlement in tempered MSS can be detected by ultrasonic velocity changes, be the acoustic frequency was $1 \mathrm{MHz}$ or $5 \mathrm{MHz}$.

(3) Ultrasonic attenuation can also be used to detect the existence of temper-embrittlement of MSS. However, higher frequency $(5 \mathrm{MHz})$ was needed to accomplish this task.

\section{Acknowledgements}

The authors wish to thank the financial support of the National Science Council (Taiwan) under project No. NSC 89-2216-E-036-020. 


\section{REFERENCES}

1) E. A. Schoefer: ASM Metal Handbook : Properties and Selection: stainless steels, tool materials and special purpose metals, 3 (Metals Park, Ohio, 1980) pp.105-106.

2) H. Y. Teng, C. H. Hsu, S. C. Chiu and D. C. Wen: Mater. Trans. 44 (2003) 1480-1487 in print.

3) K. L. Henniger: ASM Metal Handbook: Heating Treating, 4 (Metals Park, Ohio, 1991) pp. 785-792.

4) P. Mclntire: Nondestructive Testing Handbook: Ultrasonic Testing, 7 (ASNT, USA, 1991) pp.365-381.
5) P. Mclntire: Nondestructive Testing Handbook: Ultrasonic testing, 7 (ASNT, USA, 1991) pp.830-850.

6) R.L. Smith: NDT Int. 20 (1987) 43-48.

7) O. Prabhakar, R. Ambardar and Heng Keng Wah: INSIGHT 39 (1997) 100-103.

8) ASTM E 8M-97: Standard test methods for tension testing of metallic materials, 03.01 (1997) 77-97.

9) ASTM E 23-96: Standard test methods for notched bar impact testing of metallic materials, 03.01 (1996) pp. 137-156.

10) S. C. Lee and J. M. Suen: Metall. Trans. A. 20A (1989) 2399-2407. 